\title{
Generating research income: library involvement in academic research projects
}

\author{
Joanne Marsh, Gill Evans
}

\begin{abstract}
This paper considers the increasingly diverse role of the academic librarian, particularly with regard to research support and involvement in university projects and applied research. It considers how such involvement can enhance the status of the library within the institution and provide positive opportunities to promote and develop the involvement of library staff with departments across the university.

The paper focuses on the Coventry University Library's involvement with a JISC funded project D-TRACES, which sought to further embed Replay, the Siobhan Davies Dance Archive, into the curriculum in order to increase its use and uptake within teaching, learning and research. This was a joint project between the University Library and the Dance Department, and was supported by the Siobhan Davies Dance Company. The library's role in this project focused on conducting the user analysis of the existing use and take up of the resource and the production of a report that would inform the next stage of the project, to further embed Replay within teaching and learning.
\end{abstract}

\section{Introduction to the Project}

Though an institution that has traditionally focused on teaching rather than research, Coventry University is working to strengthen both its capacity and reputation for applied research; often working with organisations and companies to conduct practice-based research that also supports the teaching and research environment. Individual departments, including the library, have been set targets for research income. The University Library has been working to support this agenda through its involvement with preparations for the forthcoming REF and

\section{Authors}

Joanne Marsh is the Repository Development Librarian at Coventry University, whose team is now managing the curation of Replay.

Gill Evans is the Assistant Academic Liaison Librarian for Performing Arts at Coventry University.

Email: joanne.marsh@ coventry.ac.uk

Received 20 August 2012

Accepted 07 November 2012 
past RAEs; conducting literature reviews and searches in support of academic research projects; and the development of Coventry University's Repository for the Virtual Environment (CURVE). CURVE is the institutional repository for teaching and research outputs (Coventry University, (n.d.)).

The recent requirement for the library to generate its own research income has led to an increase in this type of activity and has made it essential that library staff actively seek opportunities for external funding around research and library developments, and where appropriate in partnership with other departments within and beyond the institution. This has lead to the formation of a library applied research group which in part seeks to identify potential projects and opportunities in order to generate research income and develop research expertise.

Academic librarians and other staff within the library must now be mindful of potential research opportunities within the University as well as being aware of potential opportunities to bid for funding from JISC (JISC, 2012) and other relevant organisations. Consequently, when a JISC call for proposals seeking to further embed and enhance existing digital resources was announced a member of library staff, with agreement from the University Librarian, took a rough and ready idea of a potential bid to the Dance department for further discussion and consideration. The proposal focused around Replay, the Siobhan Davies Dance Archive (Siobhan Davies Replay, 2009) which was a resource that the Repository Development Librarian had already worked on with the department.

Although some detail is given regarding the overall project, this paper focuses specifically on the benefits and lessons learnt from the participation of library staff in research rather than the project findings.

\section{Background to Replay and the D-TRACES Project}

The Siobhan Davies Dance Archive project began in January 2007, funded by the Arts and Humanities Research Council (AHRC) (AHRC, 2012). The project aimed to bring together all of the materials and documentation associated with Davies' choreographies into a single, fully searchable digital collection which included moving and still image, audio and text. This was a collaborative project between Siobhan Davies Dance (subsequently referred to as the Company) (Siobhan Davies Dance, (n.d.)) and Coventry University. When the online archive was launched in June 2009 it was the first of its kind in the UK and now contains approximately 3000 items relating to 36 works and 8 projects.

The D-TRACES (Dance Teaching Resources and Collaborative Engagement Space) project was funded by JISC under the e-Content and Digitisation Programme: Impact and Embedding of Digitised Resources, generating £40k for the University, with approximately £5k going directly to the library. The first stage of the project was to undertake a rapid user analysis of the existing use and take up of Siobhan Davies Replay as required by the JISC call. This part of the project was led by the library and fed into the development of strategies and practical solutions developed within the second stage of the project to ensure the increased use and impact of the resource in teaching and learning within higher education. The second aim was to embed Replay within the Personal 
Development Planning (PDP) element of the undergraduate dance curriculum at Coventry University.

Personal Development Planning (PDP) is defined by the Higher Education Academy as 'a structured and supported process undertaken by an individual to reflect upon their own learning, performance and/or achievement and to plan for their personal, educational and career development' (Higher Education Academy, 2012). It is a mandatory component for all students at Coventry University and is embedded and assessed within the first year dance module Movement Studies 1. Students are encouraged to recognize the relationship between professional arts practice, critical reflection and personal planning as well as reflections and critical analysis of their own work and that of others, outlining their vision of the nature and potential of their work as a launch pad for future careers.

\section{The bid writing process}

At Coventry University, all potential bids for external funding must go through the Business Development Support Office (BDSO). This unit leads the development of all university applied research activities and provides focused support to faculties and departments helping to identify relevant funding opportunities, costing, authorising and helping to prepare bids/proposals.

Through a series of meetings the project proposal was discussed and it became clear that the Dance Department should lead this bid. It was agreed that the library would lead on the user analysis stage and the Repository Development Librarian provided relevant information and drafted sections of the bid document relating to the activities to be undertaken by the library. During these meetings the project team agreed to involve the Assistant Academic Liaison Librarian for Dance (subsequently the Academic Librarian).

Under the terms of the project call, the project was to run for 6 months from October 2010 to March 2011. The user analysis and analysis report had to be completed within the first six weeks of the project. The Repository Development Librarian and the Academic Librarian were assigned to this task following discussions with the project team, with the recognition that our traditional professional skills would be ideally suited to this stage of the project. The distribution of the project funding reflected this involvement, bringing in direct funding for the library.

Working with the BDSO was a new and valuable experience for the Repository Development Librarian. The unit provided invaluable support regarding the University's procedures, writing bid proposals and costing the bid. However, the process created an additional layer of work and slightly shortened the deadline for submission as the final bid needed to be approved by the BDSO.

\section{Literature}

Many articles have been published which consider the role of the academic librarian in collaboration and research. These have tended to fall into two broad categories; collaboration with academic staff in delivering information skills; and involvement with library and information science (LIS) research. The idea of 
librarians collaborating with academic and research staff on discipline-based projects has not been widely considered in LIS literature.

Generally, research in libraries has tended to focus on LIS practitioner research as McNicol (2004) and Hall (2010) demonstrate. Articles such as these discuss the value and benefits of engaging with practitioner research in order to improve services or benefit the library in some way, such as research looking at user groups, marketing strategies or the introduction of new technologies (Brooks and Zubarev, 2012).

For many articles the emphasis is on the delivery of information skills sessions and collaboration with faculty is discussed largely within these parameters for example, Mounce (2010) and Lampert (2006). As Kenedy and Monty note in their paper:

There is a limited literature about the collaboration of librarians and faculty, while the literature concerning librarians and information literacy is extensive.

(Kenedy and Monty, 2011, 118)

The focus of this paper is on faculty and librarian collaboration in a faculty-led research project. Though the emphasis of the project was on embedding digital resources and the delivery of information skills sessions was part of the project work, the focus is on the librarians' involvement in the actual research project and the need to developing our wider transferable skills to work with and support academic departments more fully.

\section{Methodology}

\subsection{The overall project}

The aim of the project was to embed Replay into the undergraduate curriculum in order to enhance the students' experience of working with online resources and encourage more imaginative approaches to developing digital literacy within dance practice. Replay offers users access to different methods for documenting, collecting, organising and curating performance materials.

Students were asked to create an artist's journal, recordings of rehearsals, interviews and any other reflections of their choreographic and movement work which would contribute to their module assessment. The team built in additional sessions in the library on the use of Replay and other digital resources and practical technical sessions on recording, editing and documenting their personal journeys, and using blogs as a sketchbook and reflective tool. Dancers from the Siobhan Davies Company also ran sessions which included practical, studio based work to help demonstrate and reinforce the value of using electronic resources and social media to aid reflection and documentation of their practical activity. The development of this part of the project would be informed by the results of the user analysis to be conducted at the start of the project.

The project outcomes are not discussed in detail in this paper. Further information about the project can be found in the final project report and other documentation available on the D-TRACES project blog (D-TRACES, (n.d.)). 


\subsection{The user analysis}

The first stage of the project was to conduct the user analysis to assess the use and take up of Replay. A range of quantitative and qualitative evidence sources were applied as it was felt that use of these methods would, as Fidel notes, improve the quality of the study as:

...the biases, limitations, and weaknesses of a method following one approach are counterbalanced, or compensated for, by mixing with a method belonging to the other approach.

(Fidel, 2008, 265)

This approach was also reflected in TIDSR, the Toolkit for the impact of Digitised Scholarly Resources (Oxford Internet Institute, (n.d.)) that JISC recommended for use in developing the user analysis section of the project. TIDSR is a resource which provides guidance on quantitative and qualitative methods for measuring the impact of online resources.

Through the use of quantitative measures such as link analysis and log file analysis it was hoped the project team would gain an understanding of the frequency and extent of access which would provide base line indicators of impact and use. Google Analytics had been added to Replay and the data from September 2009 to August 2010 was analysed to give a general indication of the level of use of this resource. This data was further enriched by link analysis using Yahoo Site Explorer ${ }^{1}$ and LexiURL Searcher².

Qualitative evidence such as interviews with stakeholders and academics, user feedback and an online survey were used to compliment and enrich the quantitative data. Stakeholder interviews with representatives from Coventry University and the Company were arranged to provide background information regarding intended audience(s) and the marketing / dissemination of the resource. The online survey and interviews with academics known anecdotally to be using Replay, would provide supporting information and evidence regarding current use for teaching, research and professional practice.

Using TIDSR as an aid, a list of questions was drawn up for both the interviews and the online survey. Due to time constraints and the existing commitments of the respondents the interview questions to academic staff effectively became questionnaires, sent via email to the relevant participants along with ethical consent forms required for the University's Ethical Governance procedure. The online survey was created using Survey Monkey and was sent out to the registered users of the Archive and a number of relevant mailing lists including the Standing Conference for Dance in Higher Education (SCODHE, (n.d.)), Theatre Information Group / Society for Dance Research (TIG-SDR) (JISC mail, 2012a), Theatre and Performance Research Association (TaPRA, 2012) and the Media, Arts and Dance mailing list (JISC mail, 2012). By sending out the survey to a variety of lists it was hoped it would reach practitioners, academics and students

\footnotetext{
${ }^{1}$ Yahoo Site Explorer - Since conducting this research, Yahoo Site Explorer has been incorporated into Bing Webmaster tools - http://www.bing.com/toolbox/webmaster

${ }^{2}$ LexiURL Searcher - Since conducting this research the name of this tool has changed to Webometric Analyst http://lexiurl.wlv.ac.uk/
} 
in higher and further education and teachers in schools, thus providing a broad understanding of how the resources are used.

Although not included in the original project plan, basic bibliometric data was examined to see if and how Replay was being cited in the literature. It was hoped this would provide an insight into how the Archive might be being used for research.

\subsection{User analysis: overview of findings}

There were a number of key findings from the user analysis which not only informed the second stage of the project, but were also fed back to the Company in order to help improve the visibility and use of Replay. This section provides an overview of the key findings.

Google Analytics had been added to Replay and the data from September 2009 to August 2010 was analysed to give a general indication of the level of use and take up of this resource.

This data showed that over the year Replay received nearly 43,000 visits from 9,797 unique visitors, with $22 \%$ being new visitors. On average 2.83 pages were viewed per visit and visitors remained on the site for nearly 4 minutes, which did not seem long for such a media rich site. However, it was noted that the bounce rate was almost $75 \%$ and although care must be taken not to skew the results of this data, the removal of the bounce rate increased the average time spent on Replay to 15 minutes, with 8 pages viewed per visit. This level of usage would be more in line with expectations for a media rich site that includes images and video content.

Figures 1 and 2 show the difference in overall usage when the bounce rate is taken into consideration.

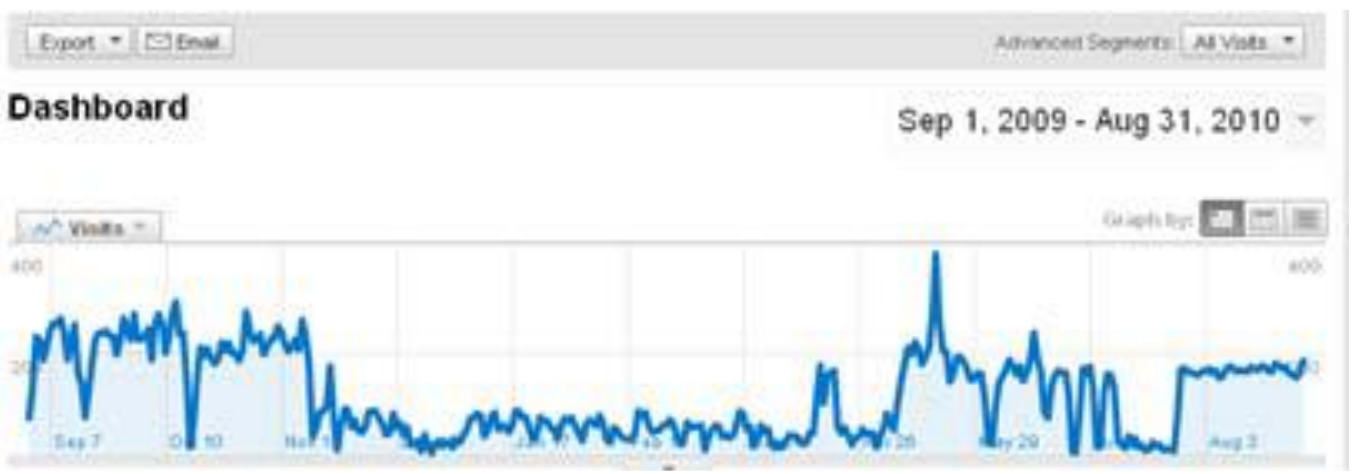

Figure 1: Google Analytics overall usage graph, with bounce rate. 


\section{Dashboard}

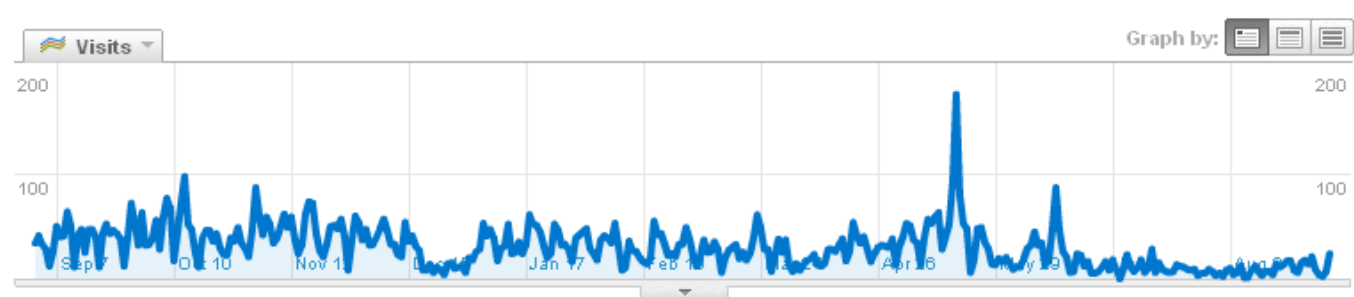

\section{Figure 2: Google Analytics overall usage, no bounce rate graph}

Data from Google Analytics revealed that the majority of users are from the UK (40,797 visits). Although usage is spread across the world, the volume of use within other countries is fairly small. Table 1 shows the visitor data for the top 10 countries using Replay.

\begin{tabular}{|c|l|c|c|c|c|c|}
\hline \multicolumn{1}{|c|}{ Country } & $\begin{array}{c}\text { Number } \\
\text { of visits }\end{array}$ & $\begin{array}{c}\text { Avg pgs per } \\
\text { visit }\end{array}$ & $\begin{array}{c}\text { Avg time on } \\
\text { site }\end{array}$ & $\begin{array}{c}\text { \% New } \\
\text { visits }\end{array}$ & $\begin{array}{c}\text { Bounce } \\
\text { rate }\end{array}$ \\
\hline 1 & United Kingdom & 40,797 & 2.76 & $00: 03: 47$ & $20.11 \%$ & $75.90 \%$ \\
\hline 2 & United States & 533 & 4.45 & $00: 03: 09$ & $69.61 \%$ & $48.59 \%$ \\
\hline 3 & Germany & 146 & 4.62 & $00: 03: 06$ & $75.34 \%$ & $51.37 \%$ \\
\hline 4 & Australia & 131 & 4.50 & $00: 03: 25$ & $82.44 \%$ & $36.64 \%$ \\
\hline 5 & Sweden & 107 & 3.95 & $00: 02: 53$ & $17.76 \%$ & $71.96 \%$ \\
\hline 6 & Portugal & 85 & 4.91 & $00: 03: 36$ & $50.59 \%$ & $51.76 \%$ \\
\hline 7 & Ireland & 82 & 4.54 & $00: 04: 37$ & $75.61 \%$ & $47.56 \%$ \\
\hline 8 & Spain & 80 & 3.14 & $00: 02: 00$ & $52.50 \%$ & $63.75 \%$ \\
\hline 9 & Netherlands & 74 & 3.95 & $00: 02: 29$ & $70.27 \%$ & $45.95 \%$ \\
\hline 10 & New Zealand & 63 & 3.86 & $00: 02: 26$ & $47.62 \%$ & $61.90 \%$ \\
\hline
\end{tabular}

Table 1: Top ten countries visiting the Archive from Google Analytics Map Overlay report for Siobhan Davies Replay 01/09/2009 - 31/08/2010

As the Company is based in London, it is perhaps no surprise that the majority of UK visits to Replay are from here (30,949 visits). The bounce rate for London is $88.21 \%$ with only 2 pages on average viewed per visit. This is higher than the average bounce rate across the site for this period, and may be reflective of a significant number of users in the area using Replay as their homepage, or making use of specific content within Replay for dance classes, events etc.

After London, Coventry is the second highest location for usage in the UK with 1,372 visits; 4.16 average pages per visit and an average of 03:52 minutes per visit. Across England the visits were fairly spread, possibly reflecting the inclusion of the Davies' work 'Bird Song' in the dance GCSE (AQA, 2010a) and 'Wyoming' in the A Level (AQA, 2010b) dance curriculums for England and Wales at the time of this study. 
Data from Google Analytics was further enriched through qualitative evidence from 2 stakeholder interviews, questionnaires returned from 4 academics regarding their use of Replay and 86 responses to the online survey. It was found that Replay was being used as an online reference source, a learning resource, a teaching resource, and to support professional dance practice.

Of those who responded to the online survey and had used the archive, 15 agreed it was important to their teaching and 23 felt it was important to their learning. 29 respondents to the online survey described themselves as lecturers or teachers with regard to their use of the archive. Of these, 13 worked within higher education, 12 within schools and 1 within further education. As previously noted, website analytics confirmed that schools had been using the site due to a number of Davies' works being on dance syllabuses.

69 respondents to the online survey said they used digital resources to support research and 31 people described themselves as researchers with regard to their use of Replay. 21 respondents agreed that Replay was important to their research and one respondent said that Replay:

...helps me re-formulate my research questions and give more ideas about an artist's practice or in following some particular archive.

Survey responses also found that Replay was used to support professional dance practice. 15 people described themselves as dance artists and 19 respondents felt that Replay was an important resource for their dance/movement practice. One respondent commented:

I am interested in looking at other choreographers' methodology or creative practice, to inform my practice. I have looked at the Siobhan Davies Replay and found it very interesting and informative about creative approaches to work.

The analysis also highlighted problems with the citation and promotion of Replay. Despite the regular promotion of the resource by the Company, users were still referring to the resource as the Siobhan Davies Dance Archive, which was the original name used by the project until just after the launch in June 2009. In the most recent article to discuss Replay, published in March 2010 (Bannon, 2010) the author still referred to the resource as the Siobhan Davies Dance Archive, and referenced the original link (http://www.siobhandaviesarchive.com). This link still automatically and seamlessly re-directs to www.siobhandaviesreplay.com without the user being aware that the URL has changed. This has implications for the ongoing promotion and identity of the resource particularly as the majority of respondents from the online survey $(90.5 \%)$ felt that digitised dance material would be essential to their future work.

Undertaking the user analysis was a learning curve for both librarians involved. Though the Repository Development Librarian had some experience of using Google analytics from her work on the institutional repository and the Academic Librarian had used Survey Monkey, neither had used other analysis tools such as Lexi URL search or had undertaken interviews / questionnaires in line with the University Ethical guidance procedure. Involvement in the project provided an opportunity to develop research skills and further understanding of the issues and processes involved. 


\section{Benefits of library involvement in departmental research}

The project provided an opportunity to demonstrate the value of involving librarians in departmental/faculty research, clearly demonstrating the nature of our core professional skills which are closely aligned to research work. It has also provided an opportunity for the librarians to extend their skills and expertise in undertaking user analysis, managing projects, writing reports and understanding the University's ethical research process.

Cross-departmental working proved particularly valuable. Working more closely within the subject, with staff who are enthusiastic and able to provide discipline specific support and advice, provided the librarians with a better understanding of the University dance department. It also revealed how the academics work as a team and how they approach course design and development.

As the second part of the project focused on embedding the use of Replay within the PDP element of the first year undergraduate course, the Academic Librarian had additional opportunities to work with students on tutorials involved with the project. Consequently, the librarian's involvement with other aspects of the course, other than information skills sessions, has reinforced the connection between the department and the library for these students; reinforcing the value of the librarian, making her more approachable and resulting in greater contact with first year students following the project. It was obvious that the department clearly appreciated her willingness to support the teaching side of this project and her engagement with the students. Overall, the project has helped the Academic Librarian in her daily duties and support of the department, as well as increasing her profile with dance academics and students.

Working with Replay has increased the librarians' awareness of the potential value of digital archives and resources for the dance discipline, both within teaching and research. It has stressed the need to keep up-to-date with such developments and be able to support students who may need to use such resources to support both their learning and dance practice.

Involvement with the project also provided opportunities for external networking. The Academic Librarian took part in a project team promotional event for Palatine, the Higher Education Academy Subject Centre for Dance, Drama and Music $^{3}$. This event provided an opportunity to share practice regarding the use of digital resources within the discipline. It also led to a visit to Coventry University from another HE dance librarian who wished to discuss the possibility of digitising an archive at their institution and how it could be embedded in teaching, learning and research. Fellow library practitioners at the event were particularly interested in the opportunity this project had given the librarians to work with dance academics on a research project, and to present alongside them at an external event.

Particularly for small scale projects, such as D-TRACES, the involvement of existing library staff rather than employing a research assistant is a more cost

\footnotetext{
${ }^{3}$ Palatine. Since completing this project the HEA Subject Centres no longer exist independently. The Palatine website and resources have been archived and are available from http://78.158.56.101/archive/palatine/resources/index.html
} 
effective way of undertaking the work involved. As the staff involved are already employed by the institution there are no issues regarding advertising posts and issuing contacts; something which can be problematic for short-term, small scale projects. By employing the Academic Librarian in particular, the project benefits from their existing knowledge of faculty staff and the workings of the department, an understanding of which is necessary for time-limited projects. Another benefit to employing non-subject researchers, such as librarians, is their impartiality and ability to approach a subject objectively. This allows them to evaluate and report findings without bias originating from a professional interest in the subject area.

By identifying the potential for this project and taking it to the academic department for discussion, we demonstrated an awareness of developments in the subject field and the research interests of the department. The value of library staff and academics working together on this research project was recognised by the project team who valued how the wider skills set and expertise available would benefit the project. This was also recognised in the feedback from the final evaluation of the project and as noted in the final project report:

The complementary skills and experiences of the project team have illustrated the benefit of working on a cross-institutional basis to support teaching and learning.

(Whatley et. al., 2011, 20)

We have also been able to demonstrate how librarians can provide additional support for research activities as well as supporting teaching and learning. Though traditionally associated with enabling others to conduct research, our involvement with this project has demonstrated our contribution to the research process and ability to use our traditional skills to conduct, rather than support, research.

\section{Project challenges and lessons learned}

Although being involved in this project was a positive experience, there were some challenges and limitations. JISC gave a timeframe of six weeks to undertake, analyse and write-up the user analysis report findings from October $1^{\text {st }}$ to November $12^{\text {th }} 2010$. This is the busiest time of year for any academic library and the two members of staff involved in the project needed to continue with their day-to-day duties whilst working on the project. The full-time Academic Librarian was removed from enquiry desk duties for four of the six weeks. This person was also covering for another member of staff who had recently left. The part-time Repository Development Librarian worked on the institutional repository, was undertaking preparatory work for the REF and was also involved in another JISC project. Consequently it was sometimes difficult to find time for the two library staff to meet together to discuss the project due to work responsibilities and working hours. Regular project meetings with the Dance Department provided a valuable way of furthering the project and discussing any issues that arose. However, the academic staff had their own tight schedule of teaching commitments, and it was not always possible for all involved to attend these meetings. Emails were used between the team to ensure the project moved forward as required. 
One of the interesting aspects of the project was being able to work with the Siobhan Davies Dance Company. During the six week user analysis stage the Company was launching their latest work (Rotor). Consequently, the person who was to provide a stakeholder interview for the project was heavily involved in the Company's new launch and was not always contactable. Eventually email responses to the questions were received from them. Also, due to time constraints, it was not possible to access the Company's log file data for the archive which would have been useful for the user analysis. Ten higher education academics were contacted for feedback regarding their use of the archive in teaching and learning. However, they were also busy with the start of the new academic year. Consequently, the planned interviews with them were not possible and it was necessary to encourage responses by email, which resulted in four responses.

An understanding of the dance community in relation to the practice of dance was essential for the librarians involved in terms of knowledge of how the community works as a discipline. Neither librarian has a degree in the discipline and at the start of the project we had a sharp steep learning curve into an awareness of dance practice. Through working with the department to support information skills for a number of years, the Academic Librarian had built up an understanding of the nature and practice of this relatively small subject community. However, this was very different to being involved in the practice of the subject itself. We had to be aware of how such the subject area operates, the terminology used, main methods of networking or disseminating information, and the fact that many professionals know one another. The latter became apparent whilst contacting the administrator of a dance mailing list to disseminate the online survey. The comment was made that the email would carry more weight if sent directly by the project lead who is well known in the dance profession, and who may possibly have more influence on the response rate.

As part of the process of gaining and using responses from stakeholders and HE academics for the user analysis report, the library staff had to create ethical approval forms to be sent out with all questionnaires. We were also asked to produce an additional ethical form to cover the students taking part in the classroom sessions for embedding Replay within course teaching. When we started to write up the form it became clear that we lacked sufficient knowledge of the requirements of the teaching session and could not therefore, produce a form that would clearly and concisely deal with the relevant ethical issues. Although the teaching staff involved in the project were happy to take over this task, it did highlight the importance of understanding the knowledge and expertise that each person could bring to the project, and the need to assign tasks to appropriate team members.

\section{Future work}

The value and success of this project has been rewarded in that we have both been approached to work on similar projects, both by the dance department and another faculty within the institution; demonstrating the success and value of our contribution to departmental research. Whilst the income generated from the library involvement in this type of research project is not large, it does provide 
further opportunities to demonstrate the variety of skills and value librarians can bring to research activity.

The relationship the library has developed with the dance department and the Company through involvement with Replay has also led to the library, and in particular the repository team, working on the management and uploading of content to the archive.

\section{Conclusion}

Though we recognise that involvement in project work is not new for many librarians, the emphasis on the library being able to generate research income has meant that it has become essential for library staff to actively engage in a broader agenda, and extend their work and skills into other areas.

Undertaking this project has increased our awareness of the various procedures involved in the research process, for example, liaising with the University's Business Support Group regarding potential bids and complying with the University Ethical Governance scheme. It has also allowed us to work closely with the academic department leading the project and has improved our working relationship with the staff involved. In raising our heads above the library parapet we have successfully demonstrated the value that librarians can bring to departmental research projects. This has highlighted the library's awareness of and ability to engage with the ongoing strategic objective of developing the University's research profile.

We hope that this project and our experience can demonstrate an alternative way the University Library and academic librarians can add value and support their departments. For library staff it is clearly an opportunity to widen skills and gain research experience. It enriches the relationship with the academic department and gives an insight into the teaching and learning agenda of the academic department. However, this requires the librarian to be proactive. It is essential to develop an awareness of the interests and research in the departments you support. You need to promote yourself with research staff and offer support with this side of their work; and in doing so, extend your current awareness activities to monitor funding opportunities that will be of interest and benefit not only to the library, but also to the staff and researchers you support.

Having a subject-specific qualification may be of some benefit depending on the discipline you are supporting and how well you know your department. However, being respectful and mindful of the nature of a discipline, how its community functions and the approach of your academics involved will help you to work with them and support their research.

Taking on additional work at a time when resources and staff time may be scarce is not to be taken lightly. This might require additional support from your colleagues, line manager and head of department, but the value that can be gained from such activity in terms of recognition from other university departments and the library's support of the wider university agenda makes it well worth the effort. 


\section{References}

AHRC (2012). Arts and Humanities Research Council [Online]. URL: http://www.ahrc.ac.uk/Pages/Home.aspx [Accessed 18.09.2012].

AQA (2010a). General Certificate of Secondary Education Performing Arts:

Dance 32312010 [Online]. URL: http://store.aqa.org.uk/qual/pdf/AQA-3231-WSP-10.PDF [Accessed 01.11. 2010].

AQA (2010b). GCE AS and A Level Specifications: Dance [Online]. URL: http://store.aqa.org.uk/qual/gce/pdf/AQA-2230-W-SP-10.PDF [Accessed 01.11. 2010].

Bannon, F. (2010). Dance: the possibilities of the discipline. Research in Dance Education, 11(1), 49-59.

Brooks, M. and Zubarev, M. (2012). Another lane on the information highway? A case study of experimenting with text message reference, The Reference Librarian, 53(3), 170-181.

Coventry University (n.d.). Curve: Coventry University's Repository for the Virtual Environment [Online]. URL: http://curve.coventry.ac.uk/open [Accessed 16.08. 2012].

D-TRACES (n.d). Dance Teaching Resources and Collaborative Engagement Space [Online]. URL: http://dancetraces.wordpress.com/ [Accessed 16.08.2012].

Fidel, R. (2008). Are we there yet?: Mixed methods research in library and information science, Library and Information Science Research, 30(4), 265-272.

Hall, H. (2010). Promoting the priorities of practitioner research engagement, Journal of Librarianship and Information Science, 41(2), 83-88.

Higher Education Academy (2012). PDP: Personal Development Planning [Online]. York: Higher Education Academy. URL:

http://www.heacademy.ac.uk/resources/detail/pdp/pdp [Accessed 18.09. 2012].

JISC (2012). JISC: Inspiring Innovation [Online]. URL: http://www.jisc.ac.uk/ [Accessed 18.09.2012].

JISC mail (2012a). TIG-SDR Home Page [Online]. URL:

https://www.jiscmail.ac.uk/cgi-bin/webadmin?A0=TIG-SDR [Accessed 16.12.12].

JISC mail (2012b). Media, Arts and Dance Home Page [Online]. URL: https://www.jiscmail.ac.uk/cgi-bin/webadmin?A0=MEDIA-ARTS-AND-DANCE [Accessed 16.12.12].

Kenedy, R. and Monty, V. (2011). Faculty-librarian collaboration and the development of critical skills through dynamic purposeful learning, Libri, 61(2), 116-124.

Lampert, L. (2006). "Getting psyched" about information literacy: a successful faculty-librarian collaboration for Educational Psychology and Counselling, The Reference Librarian, 43(89/90), 5-23. 
McNicol, S. (2004). Is research an untapped resource in the library and information profession?, Journal of Librarianship and Information Science, 36(3), 119-126.

Mounce, M. (2010). Working together: academic librarians and faculty collaborating to improve students' information literacy skills: A literature review 2000-2009, The Reference Librarian, 51(4), 300-320.

Oxford Internet Institute (n.d.). Toolkit for the Impact of Digitised Scholarly Resources (TIDSR) [Online]. URL: http://microsites.oii.ox.ac.uk/tidsr/ [Accessed 16.08.2012].

SCODHE (n.d.). Standing Conference on Dance in Higher Education (UK) [Online]. URL: http://www.scodhe.ac.uk/ [Accessed 16.12.2012].

Siobhan Davies Replay (2009). The Archive of Siobhan Davies Dance. [Online] URL: http://www.siobhandaviesreplay.com [Accessed 16.08.2012].

Siobhan Davies Dance (n.d.). Siobhan Davies Dance and Siobhan Davies Studios [Online]. URL:. http://www.siobhandavies.com [Accessed 16.08.2012].

TaPRA (2012). Theatre and Performance Research Association [Online]. URL: http://www.tapra.org/ [Accessed 16.12.12].

Whatley, S. et al. (2011). D-TRACES Final Report March 312011 [Online]. URL: http://dancetraces.files.wordpress.com/2011/04/dtraces-final-reportapril111.doc [Accessed 16.08.2012].

\section{Acknowledgement}

The D-TRACES project was funded by JISC 07/10 E-content and digitisation programmes: impact and embedding of digitised resources, in collaboration with Siobhan Davies Dance.

\section{Open access and copyright}

Library and Information Research is an open access journal. A freely available copy of this paper may be downloaded from the journal's website: http://www.cilipjournals.org.uk/lir

Copyright and associated moral rights in works published in Library and Information Research are retained by the author(s) but this paper may be used freely, with proper attribution, in educational and other non-commercial settings. 